\title{
Correlation of white cell count and CRP in acute appendicitis in paediatric patients
}

\author{
AS Withers, ${ }^{1}$ A Grieve, ${ }^{2}$ JA Loveland ${ }^{1}$ \\ ${ }^{1}$ Department of Paediatric Surgery, School of Clinical Medicine, Faculty of Health Sciences, University of the Witwatersrand, \\ Chris Hani Baragwanath Academic Hospital, South Africa \\ ${ }^{2}$ Department of Paediatric Surgery, School of Clinical Medicine, Faculty of Health Sciences, University of the Witwatersrand, \\ Nelson Mandela Children's Hospital, South Africa
}

Corresponding author: Dr Aletha Suphia Withers (withers.alta@gmail.com)

\begin{abstract}
Background: Ten per cent of children who present with abdominal pain at an emergency department are diagnosed with acute appendicitis. The diagnosis of which relies on clinical acumen, but addition of tests such as measurement of the white cell count (WCC) and C-reactive protein (CRP) are needed to decrease the morbidity associated with inappropriate surgical management. This study evaluates the sensitivity, specificity and accuracy of the WCC and CRP separately and when used in combination and evaluates whether an increased WCC and CRP are associated with complicated appendicitis.

Methods: A retrospective record review of all paediatric patients who underwent appendicectomy between June 2010 and December 2016 was conducted. Demographic data, the WCC, CRP and histology results were reviewed.

Results: 763 records were reviewed. The sensitivity and specificity of the WCC were $69.6 \%$ and $43.1 \%$ respectively and of the CRP were $95.4 \%$ and $24.5 \%$ respectively. The sensitivity was higher when both the CRP and WCC were elevated (97.47\%). A normal WCC and CRP had a specificity of 98\%, with an odds ratio of 8.69 of a patient not having appendicitis. There was a borderline significance between the WCC and the presence of acute appendicitis $(p=0.0494)$. The CRP was significant in patient with acute appendicitis $(\mathrm{p}<0.0001)$. The WCC and CRP between uninflamed appendix specimens, uncomplicated appendicitis and complicated appendicitis was significant.

Conclusion: Both increasing CRP and WCC correlates with an increased likelihood of the presence of complicated appendicitis. The chance of a patient having appendicitis with both normal WCC and CRP is low.

Keywords: white cell count, CRP, acute appendicitis, paediatric patients, paediatric surgery
\end{abstract}

S Afr J Surg 2019;57(4) http://dx.doi.org/10.17159/2078-5151/2019/v57n4a2953

\section{Introduction}

Acute appendicitis is the most common paediatric surgical emergency requiring operative intervention with more than 80000 cases per annum in the United States, ${ }^{1}$ with up to $10 \%$ of children who present with abdominal pain at an Emergency department being diagnosed with acute appendicitis. $^{2}$ Suspicion of the diagnosis of acute appendicitis is based on clinical findings, however, misdiagnosis at the initial evaluation of paediatric patients who present with abdominal pain may occur in up to $30 \%$ of patients. ${ }^{3}$ This is cause for considerable concern. It is known that a delay in diagnosis increases the likelihood of patients presenting with complicated appendicitis and misdiagnosis further increases the risk of children having unnecessary operations, thereby increasing morbidity and mortality associated with the disease. Paediatric patients present more frequently with atypical symptoms compared with their adult counterparts, and a wider differential diagnosis exists in paediatric patients who present with abdominal pain. ${ }^{4-6}$ Imaging modalities are used to aid in the diagnosis in acute appendicitis but have variable sensitivity. Abdominal ultrasound is the least invasive radiological investigation and most freely available in our institution. Its sensitivity is operator dependent, with sensitivity varying from $73-100 \%$ and specificity between $80-97 \%$. $^{7,8} \mathrm{CT}$ scans have improved diagnostic yield in aiding in the diagnosis of acute appendicitis with a sensitivity of $97-100 \%$, but are more expensive, and the increased radiation exposure to paediatric patients poses a considerable concern. ${ }^{7,9}$ Despite these radiological modalities to aid in the diagnosis, $28-57 \%$ of children under the age of 12 years, and up to $100 \%$ of patients under the age of 2 years will be misdiagnosed initially. $3,4,10$

To improve the diagnostic yield, adjuncts such as white blood cell count (WCC) and C-reactive protein (CRP) in evaluating paediatric patients with suspected acute appendicitis have become routine. Both inflammatory markers have limited specificity, since they might be raised in a host of other pathologies in patients who present with abdominal pain, such as; urinary tract infections (UTIs), 
Table 1. General descriptive statistics of paediatric patients with acute appendicitis

\begin{tabular}{|c|c|c|c|c|}
\hline \multirow[t]{3}{*}{ Variable } & \multicolumn{4}{|c|}{ Descriptive statistics } \\
\hline & Valid N & Mean & Confidence SD & Confidence SD \\
\hline & & & $-95,000 \%$ & $+95,000 \%$ \\
\hline Age at diagnosis (years) & 751 & $8,7390(+/-2.91)$ & 2,7668 & 3,0617 \\
\hline WCC $\left(\times 10^{\wedge} 9 / \mathrm{L}\right)(+/-\mathrm{SD})$ & 625 & $15,3465(+/-7.33)$ & 6,9460 & 7,7618 \\
\hline CRP (mg/L) (IQR)* & 595 & $145.00 *(188.00)$ & 110,3689 & 123,6743 \\
\hline Appendix histology** & 683 & & & \\
\hline Normal (\%) & $70(10 \%)$ & & & \\
\hline Uncomplicated (\%) & $275(40 \%)$ & & & \\
\hline Complicated (\%) & $338(50 \%)$ & & & \\
\hline
\end{tabular}

\section{* Median}

** Expressed as number and (percentage)

mesenteric lymph adenitis, neoplasms and tuberculosis (TB), which are prevalent in our paediatric population. ${ }^{6,11}$ In addition to this, there are conflicting reports on the correlation of these inflammatory markers with the presence of acute appendicitis. ${ }^{12-20}$ This retrospective study aimed to describe the correlation of WCC and CRP, alone and in combination, in paediatric patients with acute appendicitis in our population.

\section{Methods}

This study was conducted as a retrospective record review of all paediatric patients who presented to the Department of Paediatric Surgery, University of the Witwatersrand at Chris Hani Baragwanath Academic Hospital and Charlotte Maxeke Johannesburg Academic Hospitals between June 2010 and December 2016 with acute appendicitis. Records and laboratory results were reviewed to obtain demographic data on all patients; white blood cell count, C-reactive protein results from admission were recorded, and the histology of the appendix specimens was reviewed.

Normal values for WCC were based on normal reference ranges according to the age of the patient. ${ }^{15}$

Normal values for CRP were established as $<10 \mathrm{mg} / 1$ as per the local laboratory cut-off values.

\section{Statistical analysis}

Data analysis was performed using Statistica version 13 (Tibco Software Inc.). Continuous data were described in terms of means and standard deviations for data with a normal distribution, and in terms of median and interquartile ranges for non-parametric data. Categorical data are expressed as proportions. Kruskal-Wallis ANOVA tests were performed on non-parametric data and chi-square tests on categorical variables.

\section{Results}

Records for 763 children who were diagnosed with acute appendicitis and had undergone an appendicectomy were included in the study. There were 447 males included in the study. The mean WCC was $15.35 \times 10^{\wedge} 9 / \mathrm{L}$ (Range: 1.98-49.14, SD: 7.33), and median was CRP $145 \mathrm{mg} / \mathrm{L}$ (Range: 0-705, IQR: 188 ). Histology results for 683 patients were found. Appendix histology was defined as normal if there was no evidence of inflammation. Uncomplicated appendicitis was defined as inflamed, non-perforated appendicitis. Complicated appendicitis was defined as acute appendicitis with perforation, gangrenous appendicitis, presence of appendiceal abscess, or an appendix mass. Normal appendix specimens were found in $10 \%$ of patients. Forty per cent of patients had uncomplicated appendicitis, whereas 50\% of patients had complicated appendicitis. Descriptive statistics for the patients in this study are depicted in Table 1.

WCC and CRP were analysed to evaluate the sensitivity and specificity of predicting acute appendicitis in isolation, and when combined (Table 2). Age-dependent cut-off values were utilised for WCC and a CRP of greater than $10 \mathrm{mg} / \mathrm{L}$ was defined as a raised CRP, as per the values provided by our laboratory.

The WCC was noted to be above the normal range for age in $341(54.56 \%)$ patients, and below the normal range in 15 (2.40\%) patients who had acute appendicitis. 158 (25.28\%) patients had a normal WCC despite having histologically confirmed acute appendicitis. There was borderline relationship between the presence of a raised WCC and the presence of acute appendicitis on histology (chi-square test 3.861, p-value: 0.0494). The sensitivity and specificity of the WCC in predicting the presence of acute appendicitis is $69.6 \%$, and $43.1 \%$, respectively, with and accuracy of $66.90 \%$.

Chi-square test showed a strong relationship between a raised CRP, and the presence of acute appendicitis (chi-square test: 31.444 , p-value $<0.00001$ ). The CRP was more sensitive, and accurate in predicting the presence of acute appendicitis than the WCC, with a sensitivity of $95.4 \%$, and an accuracy of $88.65 \%$. The specificity of the CRP was $24.50 \%$.

When the WCC and CRP values were combined and rated as either one being raised, both negative or both raised, the presence of a combined raised WCC and CRP showed a statistically significant correlation ( $p$-value $<0.0001)$. In 


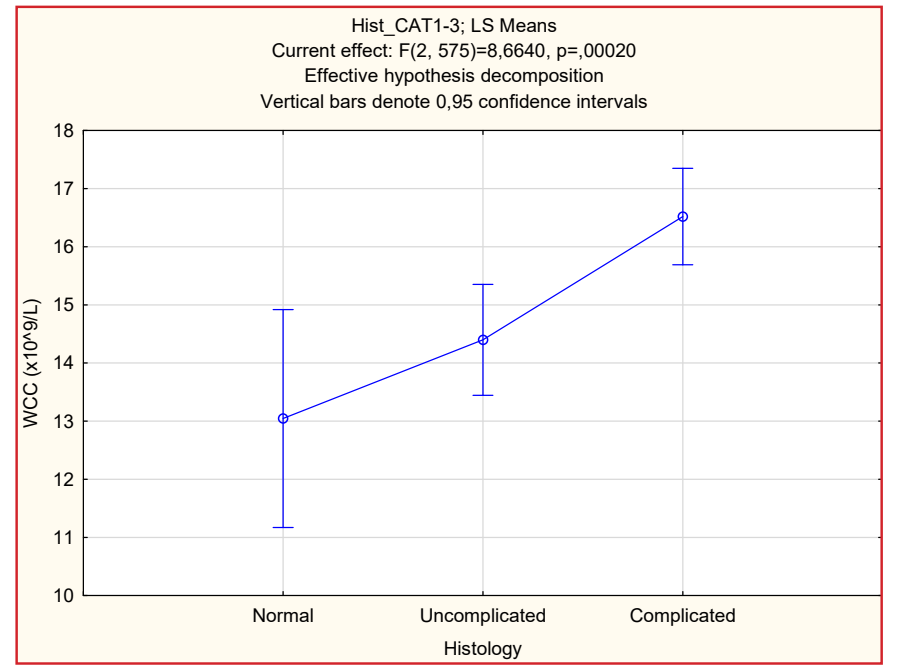

Figure 1. Tukey (HSD) test results of the WCC in normal appendix specimens, uncomplicated appendicitis and complicated appendicitis

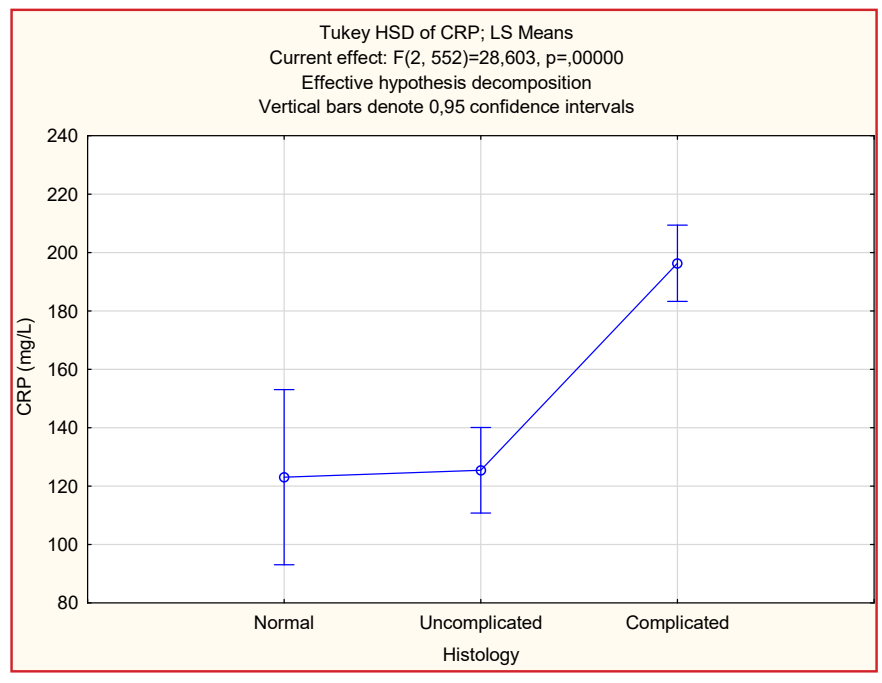

Figure 2. Tukey HSD result of the CRP in normal appendix specimens, uncomplicated appendicitis and complicated appendicitis

Table 2. Sensitivity, specificity, positive predictive value (PPV), negative predictive value (NPV), accuracy and odds ratio of inflammatory markers

\begin{tabular}{lcccccc}
\hline Variable & Sensitivity (\%) & Specificity (\%) & PPV (\%) & NPV (\%) & Accuracy (\%) & Odds ratio \\
\hline WCC & 69.6 & 43.1 & 91.60 & 13.70 & 66.90 & 1.73 \\
CRP & 95.40 & 24.50 & 92.30 & 36.10 & 88.65 & 6.77 \\
WCC raised, CRP raised & 97.47 & 23.53 & 93.70 & 44.44 & 91.28 & 10.25 \\
WCC raised, CRP normal & 56.52 & 61.54 & 72.22 & 44.44 & 58.33 & 2.08 \\
WCC normal, CRP raised & 92.96 & 38.10 & 91.03 & 44.44 & 85.89 & 8.12 \\
WCC normal, CRP normal - & 15.38 & 98.00 & 44.44 & 91.60 & 90 & 8.69 \\
no appendicitis present & & & & & &
\end{tabular}

addition to this, it was noted that the sensitivity, positive predictive value (PPV), and accuracy were increased to $97.47 \%, 93.70 \%$, and $91.28 \%$, respectively than when these markers were evaluated in isolation. Results also showed that where either the CRP or WCC were negative when the other inflammatory marker was raised that the sensitivity, specificity, PPV and accuracy were decreased compared with the sensitivity, specificity, PPV and accuracy of the CRP alone.

The association between an increasing WCC or CRP and the prevalence of complicated acute appendicitis was investigated. A Kruskal-Wallis ANOVA was performed to evaluate the effect of an increasing WCC on the severity of acute appendicitis as found on histology (normal appendix, uncomplicated appendicitis, or gangrenous/perforated appendicitis). There was a statistically significant difference in the WCC between the three groups (p-value: 0.0002). When each category was compared (using Tukey (HSD)) (Figure 1), there was a statistically significant difference between the group with complicated appendicitis $(p=0.003)$ compared to the group with uncomplicated appendicitis $(\mathrm{p}=0.003)$ and normal appendix specimens $(\mathrm{p}=0.003)$, with a mean WCC of 16.52 in the complicated appendicitis group and 14.40 and 13.05 in the uncomplicated and normal appendix specimens respectively.
A Kruskal-Wallis ANOVA was also conducted to show if there is an association between the CRP and the severity of acute appendicitis on histology. Results showed a statistically significant difference between an increasing CRP and increased severity of acute appendicitis. (p-value $<0.0001$ ). Again, there was a significant difference between the CRP of the complicated appendicitis group and that of the uncomplicated and normal appendix groups ( $\mathrm{p}<0.001$ in each group), and no statistically significant association between the CRP level and the presence of uncomplicated appendicitis compared with normal appendix specimens $(p=0.989)$. The means for the 3 categories of patients showed significant higher values than the cut-off of $10 \mathrm{mg} / \mathrm{l}$ of $123.08 \mathrm{mg} / \mathrm{l}, 125.43 \mathrm{mg} / \mathrm{l}$ and $196.32 \mathrm{mg} / \mathrm{l}$ in the normal appendix, uncomplicated appendicitis and complicated appendicitis groups respectively (Figure 2).

A combined normal WCC and CRP showed a sensitivity and specificity of $15.38 \%$ and $98 \%$ of acute appendicitis not being present, with a negative predictive value (NPV) of $91.6 \%$. The odds ratio of not having acute appendicitis when both of these tests were within the normal range was 8.69.

\section{Discussion}

Acute appendicitis is a common surgical condition and the most frequent reason for emergency surgery in the paediatric 
population in high-income countries. ${ }^{1}$ The incidence of acute appendicitis is less in low- and middle-income countries (LMICs) such as South Africa, reportedly due to a difference in diet. ${ }^{21}$ Imaging plays an increasing role in confirmation of the diagnosis prior to treatment, however in LMICs resources require increased reliance on clinical grounds with the addition of investigations such as WCC and CRP to support the diagnosis. Inflammatory markers such as the WCC and CRP have, however, been shown to have varying sensitivity and specificity in paediatric patients with acute appendicitis.

The sensitivity of the WCC in acute appendicitis ranges from $65-89.4 \%$ with a specificity of $55-80 \%$ in studies done in HICs; ${ }^{3,22-25}$ in comparison, our results show a lower sensitivity and specificity of $69.6 \%$ and $43.1 \%$, respectively. This may perhaps be attributed to the higher incidence of other infections in our populations such as tuberculosis and worm infestation. Reliance on clinical acumen and WCC has been unreliable with multiple conflicting results published. ${ }^{12-20}$ In contrast to the studies by Monsalve, Prada-Arias and Sarsu, we found a borderline statistically significant difference between an increase WCC and the presence of acute appendicitis. However, similar to other studies, we found a statistically significant association between the severity of acute appendicitis (whether complicated or not) and an increasing WCC..$^{22,23}$ We found that this association was significant when comparing the perforated appendicitis with uncomplicated appendicitis and normal appendix specimens (p-value 0.03 in each group), and no significant difference between the WCC in the normal appendix and uncomplicated appendicitis groups (p-value 0.416 ).

C-reactive protein is a known acute phase protein, and a sensitive marker of inflammation and tissue damage. The production of CRP starts within 4-6 hours of the tissue insult, and doubles its concentration every 8 hours, with a peak sensitivity at 24-48 hours after onset of the inflammatory event. ${ }^{26}$ The sensitivity and specificity of CRP vary from 43.2-89.29\%, and 40-81.9\%, respectively. ${ }^{3,5,15-20,27}$ We found a higher sensitivity of the CRP in our study $(95.4 \%)$ and found that the sensitivity of the CRP was higher than the WCC in contrast to studies by Beltran et al. and Siddique et al. ${ }^{20,28}$ Interestingly, the higher sensitivity of the CRP compared to the WCC is also reported in another South African study done by Van den Worm et al. in Paarl Hospital in which they reported greater diagnostic accuracy of the CRP compared to the WCC. ${ }^{29}$ The specificity was, however, lower at $24.5 \%$. The correlation between CRP values and the presence of acute appendicitis has been studied, with contradicting results. ${ }^{4,15,22,28}$ We found a statistically significant difference between increasing CRP and the presence of acute appendicitis as well as a significant difference between the CRP in complicated appendicitis compared to uncomplicated appendicitis in our study ( $p<0.001$ in each group). Our study, similar to the WCC results, did not show a significant difference in CRP values when comparing uncomplicated appendicitis and negative appendicectomies ( $\mathrm{p}$-value 0.989 ).

Current cut-off values provided by our laboratory were examined where CRP values of more than $10 \mathrm{mg} / \mathrm{L}$ are considered raised. We found that the NPV of the CRP was only $34.62 \%$, and that only $29.03 \%$ of patients in this study with a histologically normal appendix had a normal CRP. In addition to this, the cut-off value in our study at which the diagnostic accuracy of the CRP to discriminate between uncomplicated acute appendicitis from perforated appendicitis was a CRP of $196 \mathrm{mg} / \mathrm{L}$. This value is much higher than other studies from high-income countries where a value of $30-50 \mathrm{mg} / \mathrm{L}$ was associated with an increased likelihood of complicated appendicitis, ${ }^{3,4,14,30}$ however is in keeping with another study from South Africa, albeit from an adult cohort, where a value of $215 \mathrm{mg} / \mathrm{L}$ had a high likelihood of complicated appendicitis. ${ }^{29}$ Our study is, to our knowledge, the first in a South African context to evaluate these values in a paediatric population. These findings may be attributable to the presence of other concomitant illnesses present in our population, or due to a delay in presentation which may be due to socioeconomic factors.

When the WCC and CRP results were combined, and assessed in terms of the sensitivity and specificity, we found that the sensitivity improved to $97.47 \%$, with a positive predictive value of $93.70 \%$. This is in keeping with a study published by Beltran et al. and Siddique et al., which showed that the combination of a raised WCC and CRP had an enhanced sensitivity and accuracy in the setting of acute appendicitis. ${ }^{20,28}$ The odds ratio calculated in our study population of operating on a patient with a combination of a raised WCC and CRP and finding acute appendicitis was 10.25. Conversely, in the presence of a normal WCC and CRP, the odds ratio of finding a normal appendix was 8.69, which signifies that a normal WCC and CRP accurately predict the absence of acute appendicitis in this study population which correlates with results from other studies..$^{13,15,22}$

\section{Conclusion}

The WCC and CRP are important adjuncts to use in our paediatric patients who present with features of acute appendicitis. A raised WCC in isolation showed borderline significant correlation with the presence of acute appendicitis. Increasing CRP values, however, did correlate with the presence worsening acute appendicitis. The sensitivity and accuracy of the use of these inflammatory markers, when both WCC and CRP are raised, are markedly improved, but should still be used in conjunction with clinical signs and imaging, if available. Both increasing CRP and WCC correlated with an increased likelihood of the presence of complicated appendicitis in our study population. Perhaps even more important is the realisation that the chance of a patient having appendicitis with both normal WCC and CRP is unlikely.

\section{Ethics clearance}

Ethics clearance to conduct the study was provided by the University of the Witwatersrand Human Research Ethics Committee (Reference number: M180255). 


\section{Declaration of conflict of interest.}

The authors declare no conflict of interest.

\section{Orcid}

A Withers https://orcid.org/0000-0001-5941-9824

\section{REFERENCES}

1. Bansal S, Banever G, Karrer F, Partrick D. Appendicitis in children less than 5 years old: influence of age on presentation and outcome. Am J Surg. 2012;204(6):1031-5.

2. Wai S, Ma L, Kim E, Adekunle-Ojo A. the utility of the emergency department observation unit for children with abdominal pain. Pediatr Emerg Care. 2013;29(5):547-78.

3. Prada-Arias M, Vazquez JL, Salgado-Barreira A, GomezVeiraz J, et al. Diagnostic accuracy of fibrinogen to differentiate appendicitis from nonspecific abdominal pain in children. Am J Emerg Med. 2017;35:66-70. Available from: http://dx.doi. org/10.1016/j.ajem.2016.10.003

4. Kwan KY, Nager AL. Diagnosing pediatric appendicitis: usefulness of laboratory markers. Am J Emerg Med. 2010;28:1009-15.

5. Garcia Pena BM, Cook EF, Mandl KD. Selective imaging strategies for the diagnosis of appendicitis in children. Paediatrics. 2004;113(1):24-8.

6. Morrow SE, Newman KD. Current management of appendicitis. Semin Pediatr Surg. 2007;16(1):34-40.

7. Rothrock SG. Clinical features of misdiagnosed appendicitis in children. Ann Emerg Med. 1991;20:45-50.

8. Amland PF, Skaane P, Ronningen $\mathrm{H}$, et al. Ultrasonography and parameters of inflammation in acute appendicitis. A comparison with clinical findings. Acta Chir Scand. 1989;155:185-9.

9. Pena B, et al. Effect of an imaging protocol on clinical outcomes among pediatric patients with appendicitis. Pediatrics. 2002;110(6): 1088-93.

10. Wu HP, Chang CF, Lin CY. Predictive inflammatory parameters in the diagnosis of acute appendicitis in children. Acta Paediatrica. 2003;44(4):227-31.

11. Churchyard GJ, Mametja LD, Mvusi L, Ndjeka N, Hesseling AC, Reid A, et al. Tuberculosis control in South Africa: Successes, challenges and recommendations. S Afr Med J. 2014;104(3):244-8.

12. Grönroos JM. Do normal leukocyte count and C-reactive protein value exclude acute appendicitis in children? Acta Paediatr. 2001;90(6):649-651. Available from: https:// doi. org/10.1111/j.151-2227.2001.tb02428.x

13. Kim E, Subhas G, Mittal VK, Golladay ES. C-reactive protein estimation does not improve accuracy in the diagnosis of acute appendicitis in pediatric patients. Int J Surg. 2009;7(1):74-7. Available from: https://doi,irg/10.1016/j.ijsu.2008.11.001

14. Sack U, Biereder B, Elouahidi T, Bauer K, Keller T, Tröbs RB. Diagnostic value of blood inflammatory markers for detection of acute appendicitis in children. BMC Surgery. 2006;6(1):15. Available from: https://doi.org/10.1186/1471-2482-6-15

15. Stefanutti G, Ghirardo V, Gamba P. Inflammatory markers for acute appendicitis in children: Are they helpful? J Pediatr Surg. 2007;42(5):773-6. Available from: https://doi.org/10.1016/j. jpedsurg.2006.12.028

16. Grönroos JM, Grönroos P. Leucocyte count and C-reactive protein in the diagnosis of acute appendicitis. Br $\mathrm{J}$ Surg. 1999;86(4):501-4. Available from: https://doi.org/10.1046/ j.1365-2168.1999.01063.x

17. Mekhail P, Naguib N, Yanni F, Izzidien A. Appendicitis in paediatric age group: Correlation between preoperative inflammatory markers and postoperative histological diagnosis. Afr J Paediatr Surg. 2011;8(3):309-12. Available from: https:// doi.org/10.4103/0189-6725.91676

18. Sengupta A, Bax G, Paterson-Brown S. White cell count and C-reactive protein measurement in patients with possible appendicitis. Ann R Coll Surg Engl. 2009;91(2):113-5. Available from: https://doi.org/10.1308/003588409X359330

19. $\mathrm{Wu} \mathrm{HP}, \mathrm{Fu}$ YC. Application with repeated serum biomarkers in pediatric appendicitis in clinical surgery. Pediatr Surg Int. 2010;26(2):161-6. Available from: https://doi.org/10.1007/ s00383-009-2535-3

20. Beltran MA, Almonacid J, Vicencio A, Gutierrez J, Cruces KS, Cumsille MA. Predictive value of white blood cell count and C-reactive protein in children with appendicitis. J Pediatr Surg. 2007;42(7):1208-14. Available from: http://dx.doi. org/10.1016/j.jpedsurg.2007.02.010

21. Walker ARP, Segal I. Appendicitis: an African perspective. J R Soc Med. 1995;88:616-9.

22. Monsalve S, Ellwanger A, Montedonico S. White blood cell count and C-reactive protein together remain useful for diagnosis and staging of acute appendicitis in children. S Afr Med J. 2017;107(9):773-6. doi:10.7196/SAMJ.2017. v107i9.12206

23. Sarsu SB, Sarac F. Diagnostic value of white blood cell and C-reactive protein in paediatric appendicitis. Biomed Res Int. 2016:1-6. Available from: http://dx.doi. org/10.1155/2016/6508619

24. Bal A, Anil M, Narturk M, Ozdemir T, Arikan A, Koyluoglu $\mathrm{G}$, et al. Importance of clinical decision making by experience pediatric surgeons when children are suspected of having acute appendicitis. The reality in a high-volume pediatric emergency department. Pediatr Emerg Care. 2017;33(9):e38-e42.

25. Nazik S, Avci V, Kiraz ZK. Ischemia-modified albumin and other inflammatory markers in the diagnosis of appendicitis in children. Ulus Travma Acil Cerahi Derg. 2017;23(4):317-321.

26. Pepys MB, Hirschfield GM. C-reactive protein: a critical update. J Clin Invest. 2003;111(12):1805-12.

27. Yap T, Chen Y, Low WWX, Ong CCP, Nah SA, Jacobsen $\mathrm{AS}$, et al. A new 2-step risk-stratification clinical score for suspected appendicitis in children. J Pediatr Surg. 2015;50:2051-5. Available from: http://dx.doi. org/10.1016.j.jpedsurg.2015.08.028

28. Siddique K, Baruah P, Bhandari S, Mirza S, Harinath G. Diagnostic accuracy of white cell count and C-reactive protein for assessing the severity of paediatric appendicitis. JRSM Short Rep. 2011;2:59. doi 10.1258/shorts.2011.011025

29. Van den Worm L, Georgiou E, De Klerk M. C-reactive protein as a predictor of severity of appendicitis. S Afr J Surg. 2017;55(2):14-7.

30. Chandel V, Batt SH, Bhat MY, Kawoosa U, Yousuf A, Zargar B. Procalcitonin as the biomarker of inflammation in diagnosis of appendicitis in pediatric patients and prevention of unnecessary appendectomies. Indian J Surg. 2011;73(2):136-41. doi 10.1007/s12262-010-0214-1 